\title{
Interannual and interdecadal impact of Western North Pacific Subtropical High on tropical cyclone activity
}

\author{
Qiong $\mathrm{Wu}^{1,2} \cdot \mathrm{Xiaoch} \mathrm{Wang}^{2,3} \cdot \mathrm{Li} \mathrm{Tao}^{1}$
}

Received: 16 June 2019 / Accepted: 26 December 2019 / Published online: 7 January 2020

(c) The Author(s) 2020

\begin{abstract}
In this study, we analyzed the impacts of Western North Pacific Subtropical High (WNPSH) on tropical cyclone (TC) activity on both interannual and interdecadal timescales. Based on a clustering analysis method, we grouped TCs in the Western North Pacific into three clusters according to their track patterns. We mainly focus on Cluster 1 (C1) TCs in this work, which is characterized by forming north of $15^{\circ} \mathrm{N}$ and moving northward. On interannual timescale, the number of $\mathrm{C} 1 \mathrm{TCs}$ is influenced by the intensity variability of the WNPSH, which is represented by the first Empirical Orthogonal Function (EOF) of $850 \mathrm{hPa}$ geopotential height of the region. The WNPSH itself is modulated by the El Niño-Southern Oscillation at its peak phase in the previous winter, as well as Indian and Atlantic Ocean sea surface temperature anomalies in following seasons. The second EOF mode shows the interdecadal change of WNPSH intensity. The interdecadal variability of WNPSH intensity related to the Pacific climate regime shift could cause anomalies of the steering flow, and lead to the longitudinal shift of C1 TC track. Negative phases of interdecadal Pacific oscillation are associated with easterly anomaly of steering flow, westward shift of C1 TC track, and large TC impact on the East Asia coastal area.
\end{abstract}

Keywords Clustering analysis · Interannual · Interdecadal · Tropical cyclones · Western North Pacific Subtropical High

\section{Introduction}

Tropical cyclones (TCs) over the western North Pacific (WNP) can be highly destructive, resulting in devastating losses of human life and property in coastal regions of East Asia. Improving WNP TC prediction is crucial; however, it remains a difficult task partially due to strong interannual and interdecadal variability of these TCs.

Studies have documented the variability of WNP TC activity on subseasonal, interannual and interdecadal timescales (Wang and Chan 2002; Klotzbach 2014; Li et al.

Xiaochun Wang

xcwang@nuist.edu.cn

1 School of Atmospheric Science, Nanjing University of Information Science and Technology, Nanjing 210044, China

2 School of Marine Science, Nanjing University of Information Science and Technology, 219 Ningliu Road, Pukou District, Nanjing 210044, China

3 Joint Institute for Regional Earth System Science and Engineering, University of California at Los Angeles, Los Angeles 90095, USA
2015; Ling et al. 2016). Both the quasi-biweekly oscillation and Madden-Julian oscillation can significantly influence the TC genesis frequency (TCGF), enhancing (suppressing) TC genesis, especially over the South China Sea, in its active (break) phases (Li and Zhou 2013a, b; Zhao et al. 2016). On the interannual timescale, TC genesis locations, as well as TC intensity, are influenced by the El Niño-Southern Oscillation (ENSO). TCs tend to form over the southeastern WNP with stronger intensity during the warm phases of ENSO (Chan 1985, 2000; Wang and Chan 2002; Camargo and Sobel 2005; Han et al. 2016; Patricola et al. 2018; Zhao and Wang 2019). Other factors such as the sea surface temperature anomalies (SSTAs) in the Indian Ocean (IO) and the tropical North Atlantic (TNA) can also modulate the interannual variability of WNP TC activity (Zhan et al. 2011a, 2014; Tao et al. 2012; Cao et al. 2016; Yu et al. 2016).

On both the interannual and interdecadal timescale, the western North Pacific subtropical high (WNPSH) can significantly influence the genesis, intensity, lifetime and path of the TCs of the WNP (Wang et al. 2013; Kim and Seo 2016). Recently, decadal change of WNP TCGF has been detected, and many factors are found to be responsible for the decadal variability of WNP TC activity, including the tropical Pacific 
climate shift (Li et al. 2019), the Pacific Decadal Oscillation (PDO) (Tung et al. 2019), the Interdecadal Pacific Oscillation (IPO) (Henley et al. 2015; Li et al. 2015; Zhao et al. 2018b) and the Atlantic Multidecadal Oscillation (AMO) (Kossin et al. 2016; Zhang et al. 2018; Zhao et al. 2018a).

The abrupt decrease of WNP TCGF around 1997/1998 was reported and attributed to the phase change of the AMO or the IPO (Zhang et al. 2018; Zhao et al. 2018b). Further, studies have documented the poleward shift of WNP TCs' lifetime maximum intensity locations (Kossin et al. 2014; Song and Klotzbach 2018), while others addressed the westward shift of WNP TCs and associated the shift with global warming impact (Wu et al. 2015; Wang and $\mathrm{Wu} 2016$ ). However, most of the above studies took the WNP TCs as a whole in their analyses, without considering the diversity of location and path of the TCs. Some studies separated the WNP into the western and eastern parts, and found that the TCs over the western part are highly influenced by the SSTA in the IO (Choi et al. 2017; Bai et al. 2018). Other studies used clustering methods to group WNP TCs into different clusters, and found that the TC activities of different clusters related to the MJO in different ways (Kim and Seo 2016). The SSTAs in the eastern Pacific (EP) and central Pacific (CP) can also influence the activities of each cluster in different ways (Camargo et al. 2007a; Colbert et al. 2013; Kim and Seo 2016; Lodangco and Leslie 2016; Mei and Xie 2016). Most studies categorized the WNP TCs based on researcher-selected geographic boundaries (He et al. 2015b; Choi et al. 2017; Bai et al. 2018), and not in terms of TC paths or other key physical characteristics, which we will explore in this study following a previous research (Zhao et al. 2018b).

In this study, the WNP TCs are grouped into three categories according to their tracks, which are influenced by both their environmental factors and internal dynamics. To analyze the factors that may influence the interannual and interdecadal variability of different clusters of TCs, the intensity of WNPSH, SST over the global ocean, IPO index are also used. The rest of the paper is organized as follows. We describe our data and methodology in Sect. 2; discuss the interannual change and mechanism of Cluster 1 TCs in Sect. 3; analyze the their interdecadal variability, especially in terms of TC genesis longitude and track longitude in Sect. 4; and discuss our major findings in Sect. 5.

\section{Data and methodology}

\subsection{Data}

The 6-hourly TC track dataset from the Joint Typhoon Warning Center was used in our study (Chu et al. 2002), which includes TC locations (longitude, latitude) and maximum sustained near-surface wind speed (Vmax) among other variables. We analyzed all TCs over the WNP, between $100^{\circ} \mathrm{E}$ to the dateline with a Vmax equal to or greater than 35 knots, for a total of 1182 TCs. The frequency of TC track occurrence (TCOF) was defined as the frequency of TC tracks in each $5^{\circ} \times 5^{\circ}$ box, and we defined the tropical cyclone genesis frequency (TCGF) as the total number of TC generated over the WNP (Zhao et al. 2018b). Our analysis period is from 1970 to 2015 and we only focused on the typhoon season of June to October each year.

Monthly mean SST data, with a horizontal resolution of $2^{\circ} \times 2^{\circ}$, was from the National Oceanic and Atmospheric Administration (NOAA) Extended Reconstructed SST V5 (ERSST.v5; Huang et al. 2017). Monthly atmospheric data, including $850 \mathrm{hPa}$ wind and geopotential height, vertical zonal wind shear (VZWS) between $200 \mathrm{hPa}$ and $850 \mathrm{hPa}$; and the 850-300 hPa mass-weighted steering flowing were obtained from the National Centers for Environmental Prediction/National Center for Atmospheric Research (NCEP/ NCAR) reanalysis (Kalnay et al. 1996). The horizontal resolution of atmospheric reanalysis fields is $2.5^{\circ} \times 2.5^{\circ}$.

The IPO was firstly mentioned by Power et al. (1999) and later defined by Henley et al. (2015), focusing on the interdecadal variability of the Pacific basin SSTs. The tripole index was used to represent the IPO activity. This index is based on the differences between the SST over the central equatorial Pacific $\left(170^{\circ} \mathrm{E}-90^{\circ} \mathrm{W}, 10^{\circ} \mathrm{S}-10^{\circ} \mathrm{N}\right)$ and the SST averaged over the Northwest Pacific $\left(140^{\circ} \mathrm{E}-145^{\circ} \mathrm{W}\right.$, $\left.25^{\circ}-45^{\circ} \mathrm{N}\right)$ and Southwest Pacific $\left(150^{\circ} \mathrm{E}-120^{\circ} \mathrm{W}, 50^{\circ}-15^{\circ}\right.$ $\mathrm{S})$.

\subsection{Methods}

In this study, we used an objective clustering technique which was originally developed by Gaffney et al. (2007) and has been applied to investigate TC interannual variability by Camargo et al. (2007a, b), Mei and Xie (2016) and Zhao et al. (2018b). We classified the WNP TCs during 1970-2015 into three distinct clusters by track pattern: westward moving, northward moving, and northwestward moving. This is different from the subjective clustering method based on geographic locations (Choi et al. 2015, 2017; He et al. 2015a). We used the K-means clustering method to represent TC locations distribution as a convex combination of component density functions. This method is based on a linear regression mixture model, and one of the crucial features of the model is that it can simulate highly nonGaussian, multimodal densities. The component densities modeled geographic locations of a TC track versus time in quadratic polynomial regression functions. The model was fed the TC longitude and latitude locations, which are treated as conditionally independent variable, meaning the complete function for a TC track was a combination of TC longitude 
and latitude locations. The track of each TC was generated by one of the three different regression models. Each regression model possesses its own shape-function parameters. Given a TC track, the clustering algorithm was first to learn the parameters of all three models. It means that the assigned cluster had the highest posterior probability for the given track. An expectation maximization (EM) algorithm was also introduced for training parameters of clustering model. This algorithm iterated through the expectation ("E") and maximization ("M") steps until convergence. In our study, the algorithm was initialized by selecting the expectation ("E") randomly and then trained "M" steps. The threshold was set to $10^{-8}$ for the convergence of iteration process, and the best solution obtained from 10 steps of EM was selected to avoid poor local maxima in the parameter space. Detailed parameter settings of the clustering model can be found in Camargo et al. (2007a), Gaffney et al. (2007), Mei and Xie (2016) and Zhao et al. (2018b).

When analyzing the impact of the IPO on circulation fields, regression analyses were conducted after that the interannual variability of each variable was removed using the Fast Fourier Transform (FFT) filter. The significance test was carried out based on Student's $t$ test after adjusting the degree of freedom using the method of Bretherton et al. (1999). The June-October (JJASO) averaged $850 \mathrm{hPa}$ geopotential height anomalies over WNP was utilized to conduct EOF analysis (the trend is removed before performing EOF analysis), the first $\mathrm{PC} 1$ represents the interannual variability of WNPSH intensity while the second PC2 indicates the interdecadal change of WNPSH location. For composite analysis of interannual timescale, we chose nine strong WNPSH years (1973, 1980, 1983, 1987, 1993, 1995, 1998, 2008, and 2010) and eight weak WNPSH years $(1972,1974$, $1978,1984,1994,2001,2009$, and 2012) based on the criterion that the absolute value of the WNPSH intensity index (PC1) is more than one standard deviation away from its average. Note that most of the strong WNPSH years such as 1973, 1983, 1987, 1995, 1998, and 2010 were also decaying years of El Niño. For interdecadal timescale, we chose the two negative phases during 1970-1976 and 1998-2015, a positive phase during 1977-1997 based on the tripole index, as interdecadal change of WNPSH location (PC2).

\section{Results}

\subsection{TC clustering analysis}

Figure 1 shows three distinct TC track clusters based on our clustering analysis. There are 423 TCs in Cluster 1 (C1, Fig. 1a), accounting for $35.8 \%$ of the total 1182 TCs during 1970-2015 over the WNP. Cluster 2 (C2, Fig. 1d) and Cluster 3 (C3, Fig. 1g) account for $24.4 \%$ and $39.8 \%$ of the total, respectively. The $\mathrm{C} 1 \mathrm{TCs}$ mostly formed over the WNP north of $15^{\circ} \mathrm{N}$, under the influence of the WNPSH and moves northward in general, the black line in Fig. 1a representing the average movements of $\mathrm{C} 1$ TCs. Most of the C2 TCs, however, formed south of $15^{\circ} \mathrm{N}$ of the WNP and east of the Philippines. They tend to move northwestward. The C3 TCs formed west of $145^{\circ} \mathrm{E}$ over the tropical WNP and moved westward straightly. Most of the $\mathrm{C} 3$ TCs passed through the SCS, making landfalls over southern China and the Southeast Asia coastal area. Zhao et al. (2018b) discussed the decrease of C2 TCGF, which contributed to the recent abrupt decrease of the total WNP TCs. Some studies have shown that the $\mathrm{C} 3$ TCs were mainly impacted by the SSTA in the IO, and moderately influenced by the MJO (Zhan et al. 2011b; Li and Zhou 2013b, 2014; Bai et al. 2018). In this study, we focused on the mechanism responsible for the interannual and interdecadal variability of $\mathrm{C} 1$ TCs.

Most of the WNP TCs appeared during the typhoon season from June to October (JJASO). The number of C1 TCs during each typhoon season in 1970-2015 had large interannual variability (Fig. 1c). To analyze environmental factors that influence the number of $\mathrm{C} 1 \mathrm{TCs}$, Fig. 2 shows the regressed SSTA (Fig. 2a), JJASO-averaged geopotential height (Fig. 2b), low-level winds (Fig. 2c) and VZWS (Fig. 2d) upon the normalized time series of JJASO-averaged C1 TCGF. Clearly, the C1 TCGF was tightly related to the WNPSH. Increased number of $\mathrm{C} 1 \mathrm{TC}$ is associated with significant negative geopotential height and cyclonic circulation anomalies over the WNP (Fig. 2b) and significant negative SSTAs in both EP and IO (Fig. 2a). This may be related to the phase change of ENSO, similar to previous results (Wang et al. 2000; Xie et al. 2009; Stuecker et al. 2013, 2015; Xiang et al. 2013).

Using EOF analysis, the JJASO-averaged $850 \mathrm{hPa}$ geopotential height anomalies, after removing the linear trend from 1970 to 2015, can be separated into different spatial modes that have variability on different timescales. The first EOF mode (PC1) accounts for $58.4 \%$ of the total variance, while the second (PC2) accounts for additional $20.1 \%$. The first EOF mode shows a basin-uniform geopotential height anomaly centered at $150^{\circ} \mathrm{E}, 20^{\circ} \mathrm{N}$ (Fig. 3a). Not surprisingly, the PC1 is significantly correlated with the C1 TCGF, with a correlation coefficient of -0.59 for the period 1970-2015 (Table 1), which means that the WNPSH intensity tightly relate to TC genesis change over the WNP (Fig. 3b). The second EOF mode displays a west-east contrast of the geopotential height anomaly, and its principal component (PC2; blue line) has interdecadal variability (Fig. 3c, d). The PC2 was in a negative phase during 1970-1976 and 1998-2015, but in a positive phase during 1977-1997. More interestingly, the PC2 is significantly correlated with the JJASO-averaged 

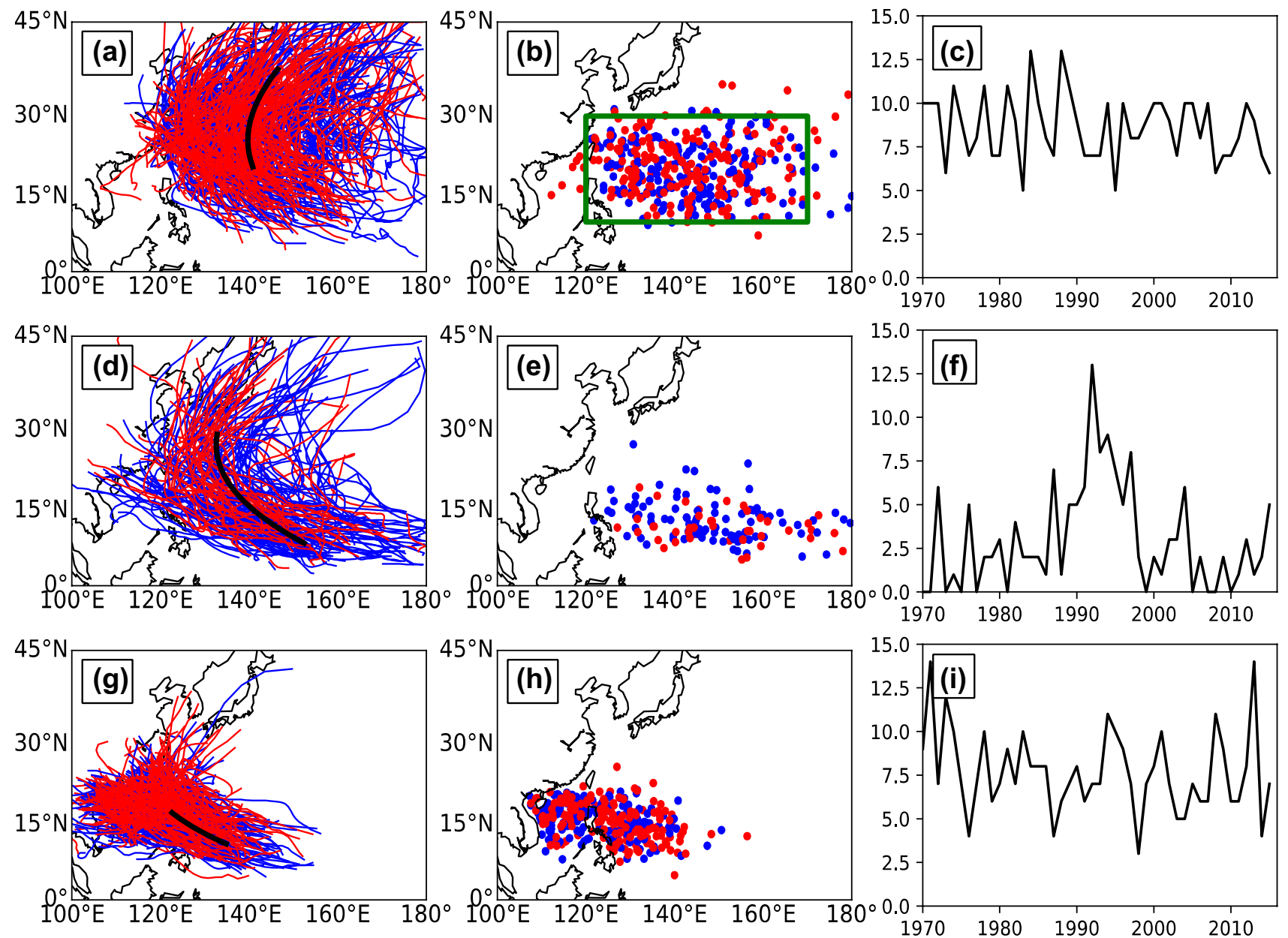

Fig. 1 Three clusters of TCs of the WNP in the typhoon season (June-October) during 1970-2015. The top panel is the TC tracks a, genesis locations of Cluster 1 (C1) b, and TCGF of $\mathrm{C} 1$ in each year c. In a, b, TCs in the positive IPO phases in 1977-1997 are shown in blue, and TCs in negative IPO phases in 1970-1976 and 1998-

IPO index (red line) in Fig. 3d, with the correlation coefficients of 0.90 in the interdecadal timescales for 1970-2015.

Table 1 shows the correlation coefficients between variables in the first column and different rows, including the TCGFs of each cluster, PC1, PC2 and the unfiltered IPO index. First, PC1, which represents the interannual variability of WNPSH intensity, is significantly correlated with the C1 TCGF, with a correlation coefficient of -0.59 over the study period. Second, PC2 is significantly correlated with the IPO index, with a correlation coefficient of 0.78 . Third, the unfiltered IPO index is significantly correlated with $\mathrm{C} 2$ TCGF (Zhao et al. 2018b), while PC2 is also significantly correlated with the IPO index. The above analysis indicates that the activity of C1 TCs is influenced by WNPSH intensity on interannual timescale, and IPO on interdecadal time scale.
2015 are shown in red. d-f Are the same as a-c, except for Cluster 2 (C2). $\mathbf{g}-\mathbf{i}$ Are the same as $\mathbf{a}-\mathbf{c}$, except for Cluster 3 (C3). The black bold lines are averaged TC tracks in $\mathbf{a}, \mathbf{d}, \mathbf{g}$. The green box is ranged around $10^{\circ} \mathrm{N}-30^{\circ} \mathrm{N}, 120^{\circ} \mathrm{E}-170^{\circ} \mathrm{E}$ in $\mathbf{b}$

\subsection{Interannual variability of C1 TC}

To analyze the mechanism of $\mathrm{C} 1 \mathrm{TC}$ on interannual timescale, Fig. 4 shows the composite differences of JJASO-averaged $850 \mathrm{hPa}$ geopotential height and winds, frequencies of TC track occurrence and TCGF between nine strong and eight weak WNPSH years as defined in Sect. 2. The composite difference of $850 \mathrm{hPa}$ geopotential height between strong and weak WNPSH years shows positive geopotential height anomalies with anomalous anticyclonic circulation over the WNP (Fig. 4a, b). Correspondingly, both the frequency of TC track occurrence and TCGF (Fig. 4c, d) significantly decreased due to the unfavorable environmental condition of positive geopotential height and anticyclonic circulation anomalies. Thus, the intensity change of WNPSH dominated the interannual variability of $\mathrm{C} 1 \mathrm{TCGF}$. 
Fig. 2 Regressed JJASOaveraged SSTA (lines in ${ }^{\circ} \mathrm{C}$ ) a, geopotential height (lines in gpm) b, winds (arrows in $\mathrm{m} / \mathrm{s}$ ) at $850 \mathrm{hPa}$, as well as vertical zonal wind shear (between 200 and $850 \mathrm{hPa}$; lines in $\mathrm{m} / \mathrm{s}$ ) d upon the JJASO-averaged normalized C1 TCGF time series from 1970 to 2015 . Areas with blue and red shadings are statistically significant at the 95\% confidence level based on the Student's t test

Fig. 3 Spatial patterns for the first $\mathbf{a}$ and second $\mathbf{c}$ EOF modes and their principal components. b Is for the first principal component ( $\mathrm{PC} 1$; blue line) time series and $\mathbf{d}$ is for the second principal component ( $\mathrm{PC} 2$; blue line) time series. The EOF analysis is based on the June to October averaged $850 \mathrm{hPa}$ geopotential height (the trend is removed before performing EOF analysis). The red line in $\mathbf{d}$ is the unfiltered IPO index from 1970 to 2015
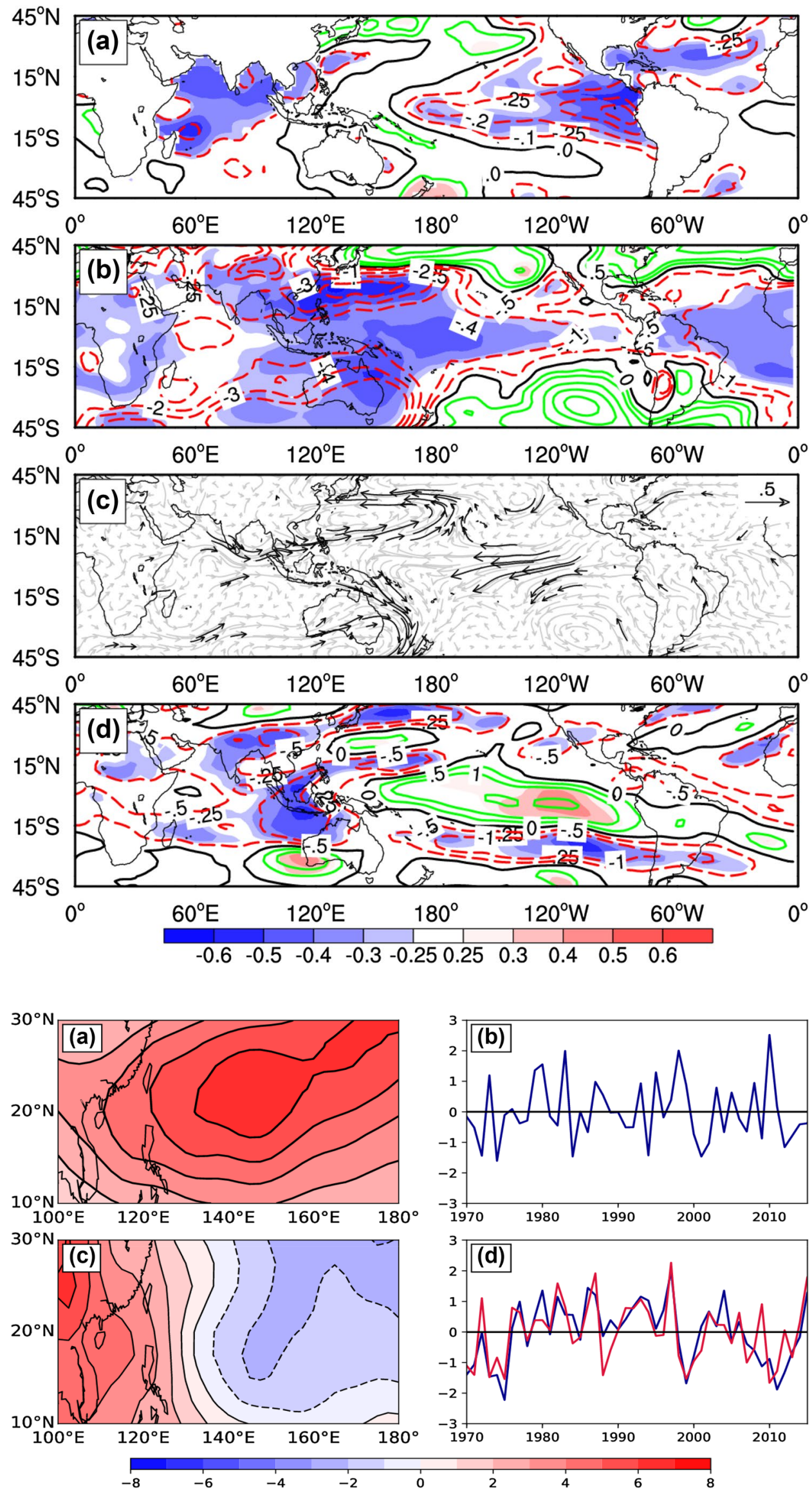
Table 1 Interannual correlation coefficients between unfiltered IPO index and TC genesis frequency in different clusters ("total" is the total number of TC genesis frequency), as well as the two time series of EOF modes over 1970-2015

\begin{tabular}{|c|c|c|c|c|c|c|c|}
\hline & $\mathrm{C} 1$ & $\mathrm{C} 2$ & C3 & Total & IPO & EOF1 & EOF2 \\
\hline C1 & 1 & -0.21 & -0.10 & 0.42 & -0.35 & -0.59 & -0.16 \\
\hline $\mathrm{C} 2$ & & 1 & 0.20 & 0.49 & 0.63 & -0.09 & -0.60 \\
\hline C3 & & & 1 & 0.53 & -0.28 & -0.27 & -0.28 \\
\hline Total & & & & 1 & 0.09 & $-\mathbf{0 . 5 3}$ & 0.16 \\
\hline IPO & & & & & 1 & -0.10 & 0.78 \\
\hline EOF1 & & & & & & 1 & 0 \\
\hline EOF2 & & & & & & & 1 \\
\hline
\end{tabular}

The boldfaced values represent statistically significant at the 95\% confidence level based on the Student's t-test
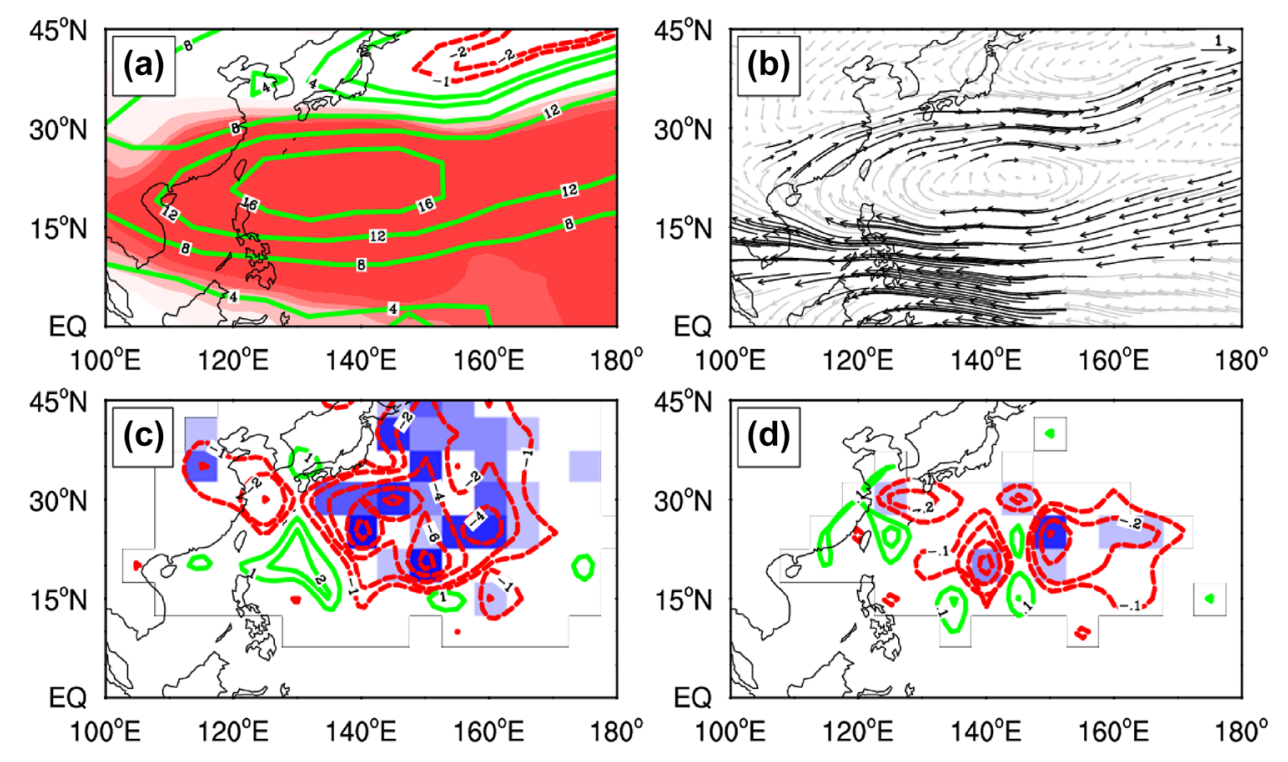

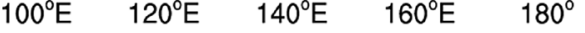

Fig. 4 Composite differences of JJASO-averaged $850 \mathrm{hPa}$ geopotential height (a; lines in $\mathrm{gpm}), 850 \mathrm{hPa}$ wind $(\mathbf{b}$; arrows in $\mathrm{m} / \mathrm{s})$, TC track (c; lines in count), and TCGF (d; lines in count) between nine strong WNPSH years $(1973,1980$, 1983, 1987, 1993, 1995, 1998, 2008, and 2010) and eight weak WNPSH years $(1972,1974$, 1978, 1984, 1994, 2001, 2009, and 2012). The shadings in a, c and $\mathbf{d}$ and the black vectors in $\mathbf{b}$ represent the areas that are significant at the $95 \%$ confidence level based on Student's t test
Since several weak WNPSH years were also the decaying years of El Niño events, it should be interesting to analyze the relationship between El Niño events and TC activity. Figure 5 displays the regressed SSTAs from previous winter (DJF) to following summer (JJASO) on the normalized JJASO-averaged PC1. The intensity of WNPSH in the following summer is related with EP SST anomaly at the peak phase of ENSO, i.e., previous DJF, whereas the correlation is relatively weak over the IO and TNA basins (Fig. 5a). During MAM, the correlation over the EP weakens while it is strengthened over the IO and the TNA from, which indicates that both the IO and NTA play roles in storing the heat due to the ENSO impact during its decaying (Du et al. 2009; Xie et al. 2009). So, the C1 TCGF can be significantly influenced by the ENSO, and this impact is sustained due to the capacity effect of the IO and TNA.

We then examined the evolution of $850 \mathrm{hPa}$ wind from previous winter (DJF) to following summer (JJASO) regressed on the normalized JJASO-averaged WNPSH index PC1. The El Niño can induce strong equatorial easterly anomalies over the western part of WNP, as well as a weak anomalous anticyclonic circulation over the Philippines (Fig. 6a). During its decaying period, the El Niño warms the IO and the TNA, intensifying the anticyclone in the following TC season and significantly suppressing C1 TC genesis over the WNP (Fig. 6b, c). Previous studies (Zhan et al. 2011a, b, 2014; Yu et al. 2016) have already discussed the relay effect of Indian Ocean (IO) and Atlantic Ocean (ATL) SSTAs from the decaying ENSO, which persist to affect the TCs over the WNP. After calculating the monthly lead-lag correlation coefficients between JJASO-averaged WNPSH index and Niño3.4 (IO and ATL SST indices) from previous December to following October (Fig. 7), we found that the highest correlation coefficient between WNPSH and Niño3.4 appears in previous December, and slowly decreases from January to October with the increased impact of IO and ATL SSTAs on the WNPSH from spring to summer. The IO and ATL SSTAs affect the WNPSH and eventually modulate the TCs (JJASO) over the WNP. 
Fig. 5 The regression of DJFaveraged $\mathbf{a}$, MAM-averaged $\mathbf{b}$ and JJASO-averaged $\mathbf{c}$ SSTAs onto the JJASO-averaged $850 \mathrm{hPa}$ geopotential height anomalies normalized first principal component (PC1) time series. Areas with blue and red shadings are statistically significant at the $95 \%$ confidence level based on the Student's t test

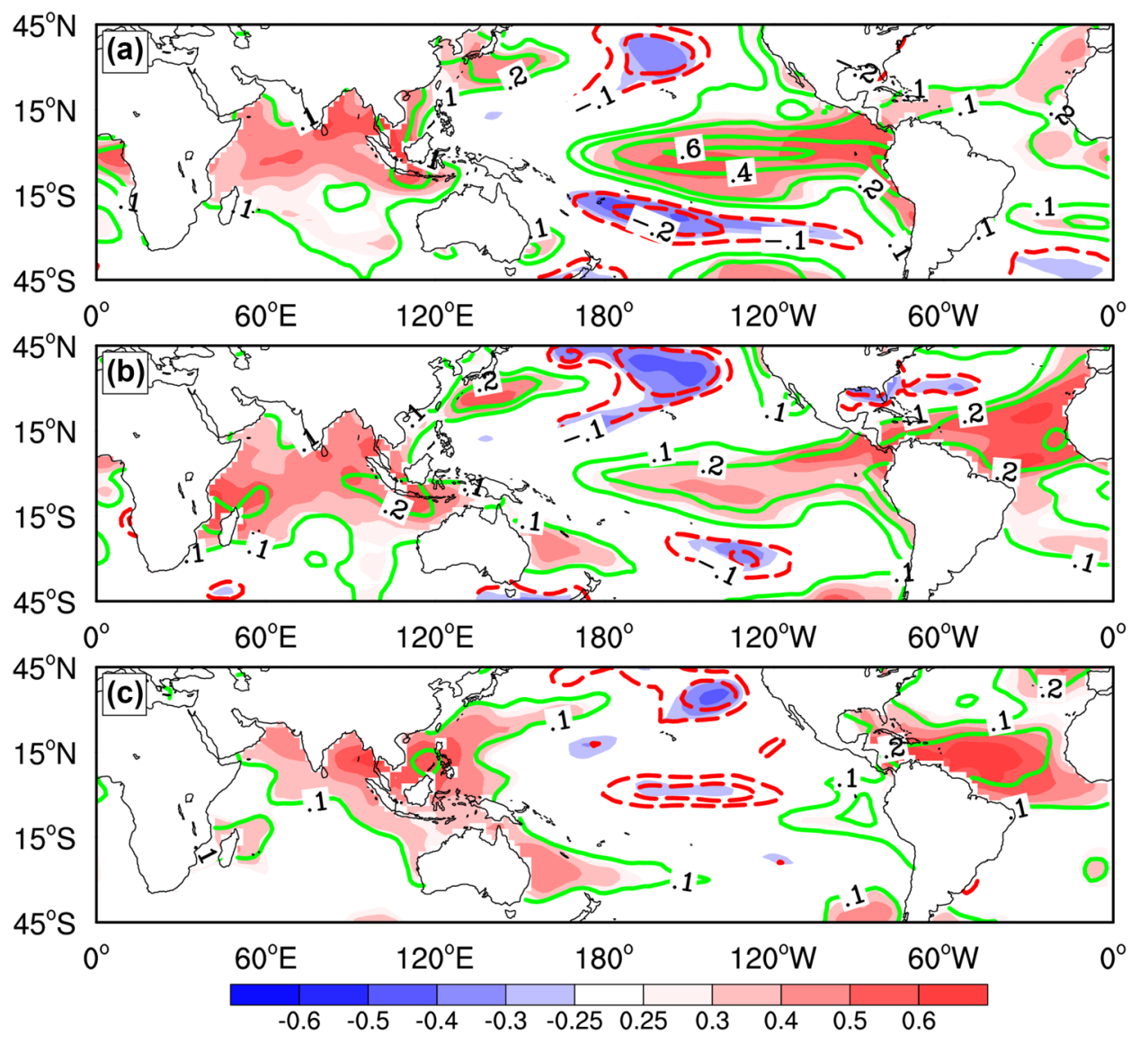

\section{Impact of the WNPSH on interdecadal change of C1 TC longitude}

The second EOF of WNPSH has interdecadal variability, which was not discussed extensively by previous works. We investigate the influence of interdecadal variability of WNPSH on C1 TC tracks (Fig. 8), by comparing the time series of unfiltered (Fig. 8a, b) and filtered (Fig. 8c, d) IPO index (red), PC2 (WNPSH, dashed red), the JJASO-averaged TC genesis longitude (black) and track longitude (blue).

First, we can see that the unfiltered PC2 (IPO) index is significantly correlated with track locations of $\mathrm{C} 1 \mathrm{TCs}$ from 1970 to 2015 with the correlation coefficient 0.29 (Fig. 8a) and the correlation is even higher $(r=0.44)$ between PC2 and annual-averaged genesis locations (Fig. 8b). From 1977 to 1997 , the PC2 (IPO) was in its positive phase and the PC2 (IPO) was in negative phase before 1977 and after 1997 in our analysis period. The TC genesis and track longitudes also show the consistent interdecadal change with the $\mathrm{PC} 2$, higher during the positive phase and lower during the negative phase, which means that during positive IPO phases both TC genesis and track locations shift eastward and vice versa. Further, we calculated the correlation coefficients after removing the interannual signals $(<10$ years $)$ using FFT. The PC2 is highly correlated with both $\mathrm{C} 1 \mathrm{TC}$ genesis and track longitude, both significant with the respective coefficient 0.61 and 0.52 after adjusting the degree of freedom (Bretherton et al. 1999). Both PC2 and C1 TC genesis longitude are also significantly correlated with the IPO index (Fig. 8), with a correlation coefficient of 0.90 between PC2 and the IPO, 0.63 between C1 TC genesis longitude and the IPO. The genesis and track location indices show consistent variability and phase shifts with the IPO. Lastly, we regressed the SSTAs onto the PC2 index (Fig. 9) after removing the interannual variability. From Fig. 9, we can see that the second mode of WNPSH is dominated by the IPO pattern. In general, the phase shift of PC2 is consistent with the change of the IPO, suggesting that the IPO may affect the west-east movements of the WNPSH (Fig. 3c) and lead to the west-east shift of $\mathrm{C} 1 \mathrm{TC}$ genesis locations and $\mathrm{C} 1$ tracks.

Based on different phases of the IPO, we did composites of the JJASO-averaged WNPSH, $850 \mathrm{hPa}$ wind, frequency of TC track occurrence, and TCGF between negative IPO phases (1970-1976 and 1998-2015) and positive IPO phases (1977-1997) (Fig. 10). During negative phase of IPO, the WNPSH was intensified with positive anomaly over the eastern part of the WNP. The composite of SSTA between negative and positive phases show a clear negative IPO pattern (Fig. 10e). The positive anomaly of $850 \mathrm{hPa}$ geopotential height was coincided with an anomalous geostrophic 
Fig. 6 The regression of DJFaveraged $\mathbf{a}$, MAM-averaged $\mathbf{b}$ and JJASO-averaged $\mathbf{c} 850 \mathrm{hPa}$ winds onto the JJASO-averaged $850 \mathrm{hPa}$ geopotential height anomalies normalized first principal component (PC1) time series. Areas with black vectors are statistically significant at the 95\% confidence level based on the Student's t-test
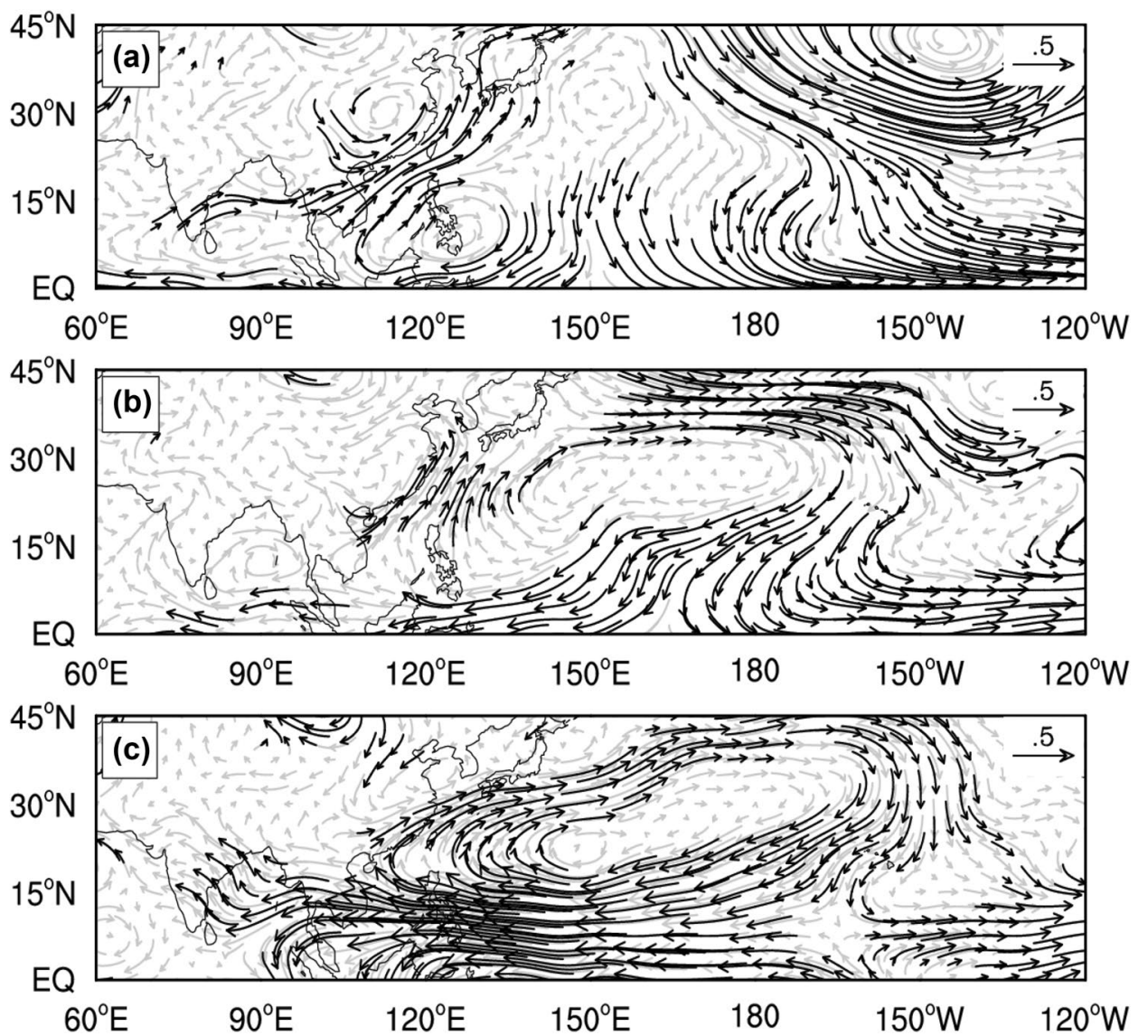

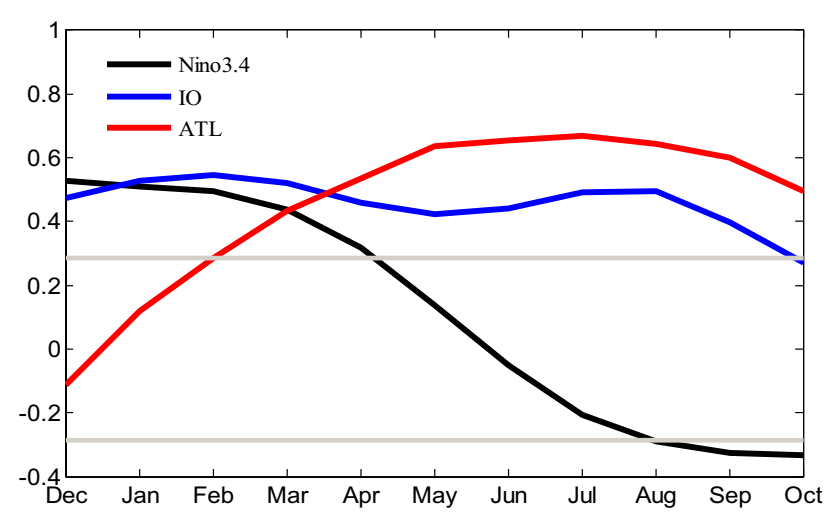

Fig. 7 Lead-lag correlation coefficients between JJASO-averaged WNPSH and Niño3.4, Indian Ocean (IO), and Atlantic Ocean (ATL) SST indices from previous winter (December) to following October during the year of 1970 and 2015. All the time series are detrended before we calculate the correlation coefficients

flow over the subtropical region (Fig. 10a) in the negative IPO phase. The intensified WNPSH leads to easterly anomalies of the 850-300 hPa steering flow (Fig. 10b) and further drives the westward shift of the TC track longitude (Fig. 10c), as well as the TC genesis longitude (Fig. 10d), resulting in increased threats to Japan and part of East China.

\section{Conclusion and discussion}

We used clustering analysis to categorize the WNP TCs into three clusters (Fig. 1), the C2 TCs and C3 TCs were discussed in Zhao et al. (2018b), Zhan et al. (2011a, b) and Li and Zhou (2013b, 2014). In this study, we mainly focused on the $\mathrm{C} 1 \mathrm{TCs}$, which mostly formed north of $15^{\circ} \mathrm{N}$ over the WNP, and tended to move northward. The first EOF mode of JJASO-averaged $850 \mathrm{hPa}$ geopotential height over the region $10^{\circ} \mathrm{N}-30^{\circ} \mathrm{N}, 100^{\circ} \mathrm{E}-180^{\circ}$ (Wang et al. 2013), representing the WNPSH, shows significant interannual variability. The WNPSH dominated the C1 TCGF over the WNP. The positive WNPSH anomaly was accompanied by anomalous anticyclonic wind, significantly reducing $\mathrm{C} 1 \mathrm{TC}$ genesis, and vice versa (Fig. 4). The intensity change of the WNPSH was influenced by the ENSO events of previous winter (Fig. 5). The decaying ENSO stored heat in the IO and TNA, and continued to affect the WNPSH and eventually modulate the C1 TCGF in the following typhoon season (JJASO) through teleconnections over the WNP.

The PC2 of WNPSH (Fig. 3d) was in positive phase for the period 1977-1997, but in negative phase both before and after that, which shows a clear interdecadal variability, 

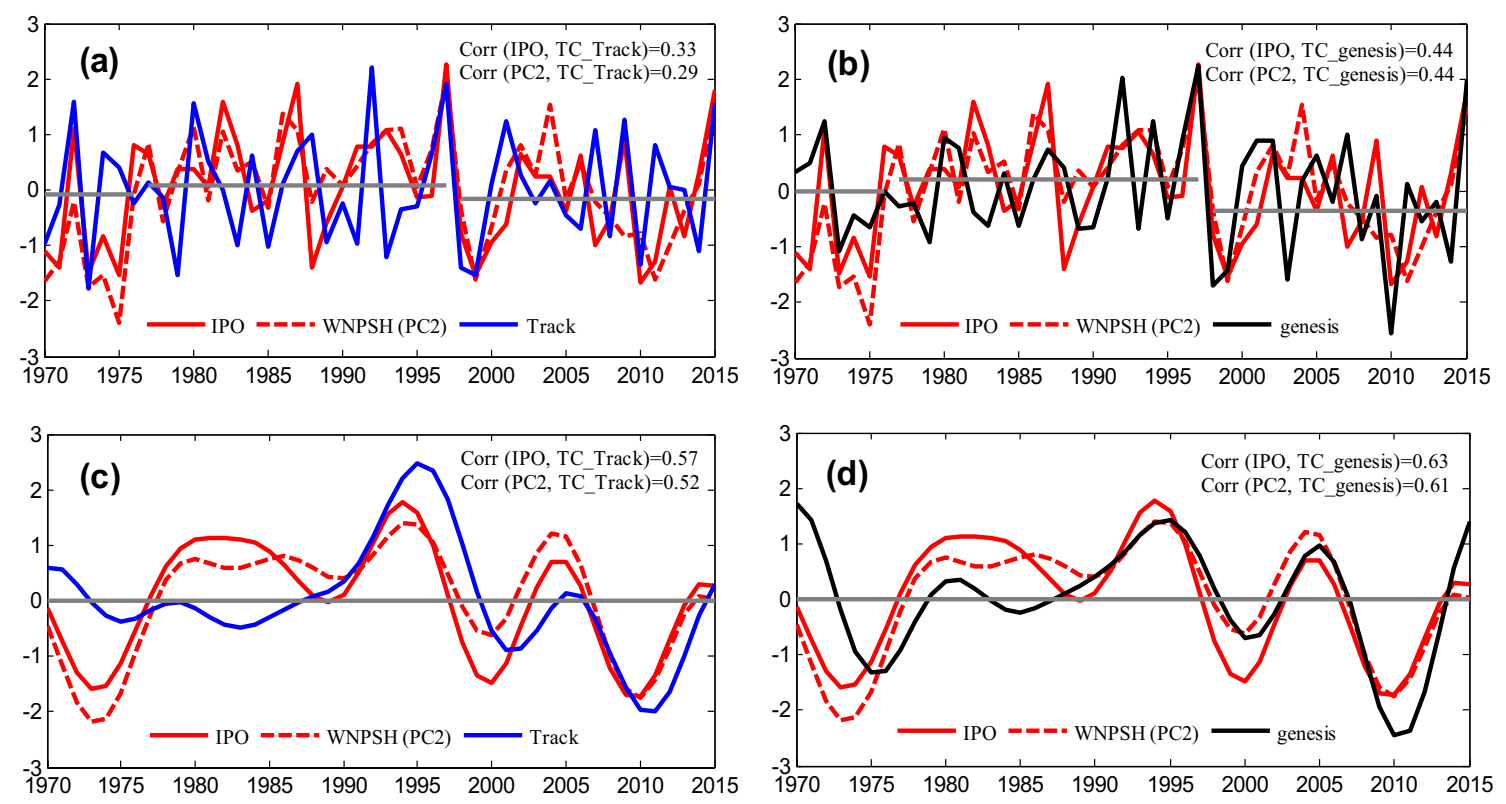

Fig. 8 Time series of JJASO-averaged IPO (red), WNPSH (PC2, dashed red) and averaged $\mathrm{C} 1$ track longitude (blue, in a), as well as genesis longitude for C1 TCs (black, in b) during 1970-2015. The

time series are original in $\mathbf{a}, \mathbf{b}$. The time series are filtered using FFT with interannual signals ( $<10$ years) removed in $\mathbf{c}$ and $\mathbf{d}$

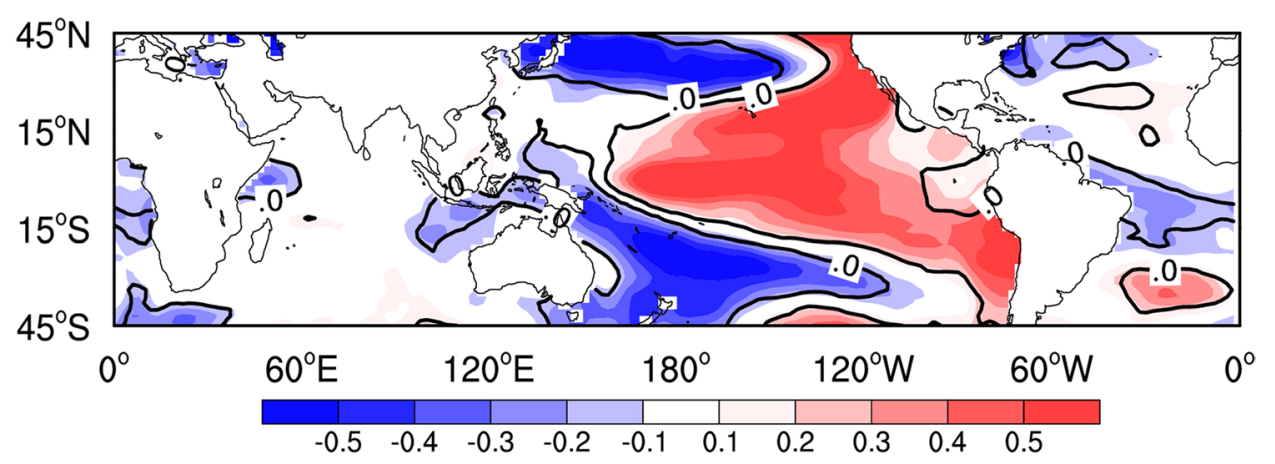

Fig. 9 Regressed SSTAs onto the normalized sign-inverted second principal component (PC2) time series derived from the JJASOaveraged $850 \mathrm{hPa}$ geopotential height with the interannual component removed using the FFT. The shading is for the regressed SST values.

consistent with the phase of the IPO. Further analysis indicated that the IPO dominated the second mode of WNPSH, inducing the pressure and wind anomalies over the WNP. Although the C1 TCGF has no significant relationship with IPO or PC2, both the averaged TC genesis longitude and averaged TC track longitude have significant correlation
The areas with black lines are statistically significant at the $95 \%$ confidence level based on the Student's t-test after adjusting the degrees of freedom

with IPO, as well as with PC2 (Fig. 8). The composite differences of $\mathrm{C} 1 \mathrm{TC}$ tracks between the negative and positive IPO phases suggests that the steering flow anomaly could guide $\mathrm{C} 1 \mathrm{TCs}$ more often to the coastal region during the negative IPO phase than during the positive phase. 
Fig. 10 Composite differences of JJASO-averaged $850 \mathrm{hPa}$ geopotential height (a; lines in gpm), 850-300 hPa mass-weighted steering flow (b; arrows in m/s), TC track (c; lines in count), TCGF (d; lines in count) and SSTA (e; lines in ${ }^{\circ} \mathrm{C}$ ) between negative IPO phases (1970-1976 and 1998-2015) and positive IPO phase (1977-1997). The shadings in $\mathbf{a}, \mathbf{c}, \mathbf{d}$ and $\mathbf{e}$ and the black vectors in $\mathbf{b}$ represent the areas that are significant at $95 \%$ confidence level based on the Student's t-test
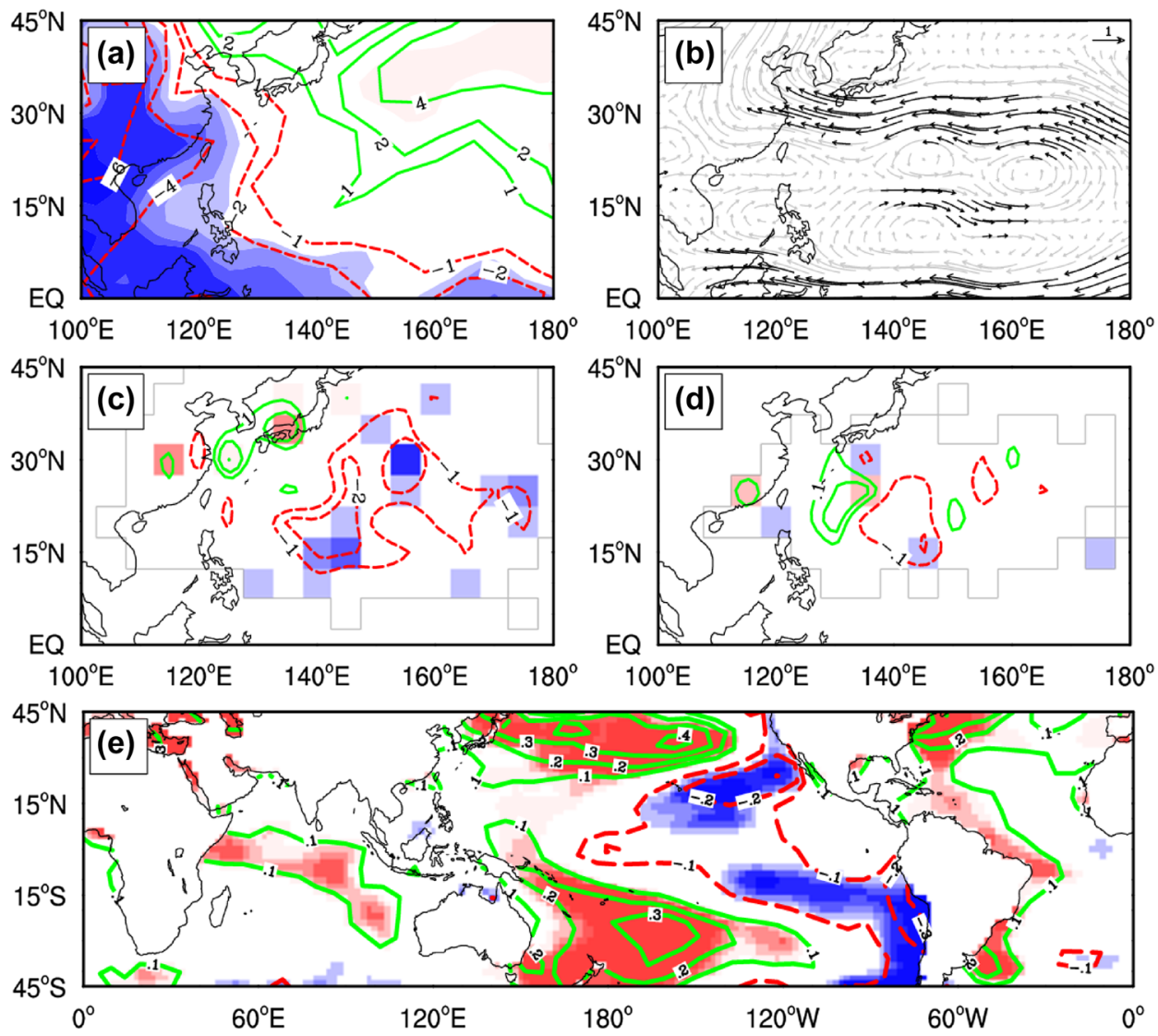

Acknowledgements This work has been supported by NSF of China (41630423, 91637209), and National Key Research and Development Program of China (2016YFA0600402), the Strategic Priority Research Program of Chinese Academy of Sciences (Grant no. XDA20060500). The comments from two reviewers are very helpful for the revision of the manuscript. The JTWC best track TC data are available at https:// metoc.ndbc.noaa.gov/web/guest/jtwc/best_tracks. The monthly mean SST data are from https://www.esrl.noaa.gov/psd/data/gridded/data. noaa.ersst.v4.html. The NCEP/NCAR reanalysis I data are obtained from https://www.esrl.noaa.gov/psd/data/gridded/data.ncep.reanalysis .html. The unfiltered Tripole Index data for the IPO are downloaded from https://www.esrl.noaa.gov/psd/data/timeseries/IPOTPI/. The clustering model for TCs is available at http://www.datalab.uci.edu/ resources/CCT.

Open Access This article is licensed under a Creative Commons Attribution 4.0 International License, which permits use, sharing, adaptation, distribution and reproduction in any medium or format, as long as you give appropriate credit to the original author(s) and the source, provide a link to the Creative Commons licence, and indicate if changes were made. The images or other third party material in this article are included in the article's Creative Commons licence, unless indicated otherwise in a credit line to the material. If material is not included in the article's Creative Commons licence and your intended use is not permitted by statutory regulation or exceeds the permitted use, you will need to obtain permission directly from the copyright holder. To view a copy of this licence, visit http://creativecommons.org/licenses/by/4.0/..

\section{References}

Bai C, Zhang R, Bao R, Liang XS, Guo W (2018) Forecasting the tropical cyclone genesis over the Northwest Pacific through identifying the causal factors in cyclone-climate interactions. J Atmos Ocean Technol 35:247-259. https://doi.org/10.1175/JTECH -D-17-0109.1

Bretherton CS, Widmann M, Dymnikov VP, Wallace JM, Bladé I (1999) The effective number of spatial degrees of freedom of a time-varying field. J Clim 12:1990-2009. https://doi. org/10.1175/1520-0442\%281999\%29012\%3c1990\%3ATEN OSD $\% 3 \mathrm{e} 2.0 . \mathrm{CO} \% 3 \mathrm{~B} 2$

Camargo SJ, Sobel AH (2005) Western North Pacific tropical cyclone intensity and ENSO. J Clim 18:2996-3006. https://doi. org/10.1175/JCLI3457.1

Camargo SJ, Robertson AW, Gaffney SJ, Smyth P, Ghil M (2007a) Cluster analysis of typhoon tracks. Part I: general properties. J Clim 20:3635-3653. https://doi.org/10.1175/JCLI4188.1

Camargo SJ, Robertson AW, Gaffney SJ, Smyth P, Ghil M (2007b) Cluster analysis of typhoon tracks. Part II: large-Scale circulation and ENSO. J Clim 20:3654-3676. https://doi.org/10.1175/ JCLI4203.1

Cao X, Chen S, Chen G, Wu R (2016) Intensified impact of northern tropical Atlantic SST on tropical cyclogenesis frequency over the western North Pacific after the late 1980s. Adv Atmos Sci 33:919-930. https://doi.org/10.1007/s00376-016-5206-z 
Chan JCL (1985) Tropical cyclone activity in the Northwest Pacific in relation to the El Niño/Southern Oscillation phenomenon. Mon Weather Rev 113:599-606. https://doi.org/10.1175/15200493(1985)113\%3c0599:TCAITN\%3e2.0.CO;2

Chan JCL (2000) Tropical cyclone activity over the Western North Pacific associated with El Niño and La Niña Events. J Clim 13:2960-2972. https://doi.org/10.1175/15200442(2000)013\%3c2960:TCAOTW\%3e2.0.CO;2

Choi Y, Ha KJ, Ho CH, Chung CE (2015) Interdecadal change in typhoon genesis condition over the western North Pacific. Clim Dyn 45:3243-3255. https://doi.org/10.1007/s00382-015-2536-y

Choi JW, Cha Y, Kim T, Kim HD (2017) Interdecadal variation of tropical cyclone genesis frequency in late season over the western North Pacific. Int J Climatol 37:4335-4346. https://doi. org/10.1002/joc. 5090

Chu J-H, Sampson CR, Lavine A, Fukada E (2002) The Joint Typhoon Warning Center tropical cyclone best-tracks, 1945-2000. Naval Research Laboratory Tech. Rep. NRL/MR/7540-02-16

Colbert AJ, Soden BJ, Vecchi GA, Kirtman BP (2013) The impact of anthropogenic climate change on North Atlantic tropical cyclone tracks. J Clim 26:4088-4095. https://doi.org/10.1175/JCLID-12-00342.1

Du Y, Xie S-P, Huang G, Hu K (2009) Role of air-sea interaction in the long persistence of El Niño-Induced north Indian Ocean warming. J Clim 22:2023-2038. https://doi.org/10.1175/2008JCLI2590.1

Gaffney SJ, Robertson AW, Smyth P, Camargo SJ, Ghil M (2007) Probabilistic clustering of extratropical cyclones using regression mixture models. Clim Dyn 29:423-440. https://doi.org/10.1007/ s00382-007-0235-z

Han R, Wang H, Hu ZZ et al (2016) An assessment of multi-model simulations for the variability of western North Pacific tropical cyclones and its association with ENSO. J Clim 29:6401-6423. https://doi.org/10.1175/JCLI-D-15-0720.1

He C, Zhou T, Lin A, Wu B, Gu D, Li C, Zheng B (2015a) Enhanced or weakened western North Pacific subtropical high under global warming? Sci Rep 5:16771. https://doi.org/10.1038/srep16771

He H, Yang J, Gong D, Mao R, Wang Y, Gao M (2015b) Decadal changes in tropical cyclone activity over the western North Pacific in the late 1990s. Clim Dyn 45:3317-3329. https://doi. org/10.1007/s00382-015-2541-1

Henley BJ, Gergis J, Karoly DJ, Power S, Kennedy J, Folland CK (2015) A tripole index for the interdecadal Pacific oscillation. Clim Dyn 45:3077-3090. https://doi.org/10.1007/s0038 2-015-2525-1

Huang B, Thorne PW, Banzon VF, Boyer T, Chepurin G, Lawrimore JH, Menne MJ, Smith TM, Vose RS, Zhang HM (2017) Extended reconstructed sea surface temperature version 5 (ERSSTv5), upgrades, validations, and intercomparisons. J Clim 30:81798205. https://doi.org/10.1175/JCLI-D-16-0836.1

Kalnay E et al (1996) The NCEP/NCAR 40-year reanalysis project. Bull Am Meteorol Soc 77:437-471. https://doi.org/10.1175/15200477(1996)077\%3c0437:TNYRP\%3e2.0.CO;2

Kim H-K, Seo K-H (2016) Cluster analysis of tropical cyclone tracks over the western North Pacific using a self-organizing map. J Clim 29:3731-3751. https://doi.org/10.1175/JCLI-D-15-0380.1

Klotzbach PJ (2014) The Madden-Julian Oscillation's impacts on worldwide tropical cyclone activity. J Clim 27:2317-2330. https ://doi.org/10.1175/JCLI-D-13-00483.1

Kossin JP, Emanuel KA, Vecchi GA (2014) The poleward migration of the location of tropical cyclone maximum intensity. Nature 509:349-352. https://doi.org/10.1038/nature13278

Kossin JP, Emanuel KA, Camargo SJ (2016) Past and projected changes in western North Pacific tropical cyclone exposure. J Clim 29:5725-5739. https://doi.org/10.1175/JCLI-D-16-0076.1
Li RCY, Zhou W (2013a) Modulation of western North Pacific tropical cyclone activity by the ISO. Part I: genesis and intensity. J Clim 26:2904-2918. https://doi.org/10.1175/JCLI-D-12-00210.1

Li RCY, Zhou W (2013b) Modulation of western North Pacific tropical cyclone activity by the ISO. Part II: tracks and landfalls. J Clim 26:2919-2930. https://doi.org/10.1175/JCLI-D-12-00211.1

Li RCY, Zhou W (2014) Interdecadal change in South China Sea tropical cyclone frequency in association with zonal sea surface temperature gradient. J Clim 27:5468-5480. https://doi.org/10.1175/ JCLI-D-13-00744.1

Li W, Li L, Deng Y (2015) Impact of the Interdecadal Pacific Oscillation on tropical cyclone activity in the North Atlantic and Eastern North Pacific. Sci Rep 5:12358. https://doi.org/10.1038/srep12358

Li X, Hu ZZ, Becker E (2019) On the westward shift of tropical Pacific climate variability since 2000. Clim Dyn 53:2905-2918. https:// doi.org/10.1007/s00382-019-04666-8

Ling Z, Wang Y, Wang G (2016) Impact of intraseasonal oscillations on the activity of tropical cyclones in summer over the South China Sea. Part I: local tropical cyclones. J Clim 29:855-868. https://doi.org/10.1175/JCLI-D-15-0617.1

Lodangco ILC, Leslie LM (2016) Cluster analysis of Philippine tropical cyclone climatology: applications to forecasting. J Climatol Weather Forecast 04:152. https://doi.org/10.4172/23322594.1000152

Mei W, Xie S-P (2016) Intensification of landfalling typhoons over the northwest Pacific since the late 1970s. Nat Geosci 9:753-757. https://doi.org/10.1038/ngeo2792

Patricola CM, Camargo SJ, Klotzbach PJ, Saravanan R, Chang P (2018) The influence of ENSO flavors on western north pacific tropical cyclone activity. J Clim 31:5395-5416. https://doi.org/10.1175/ JCLI-D-17-0678.1

Power S, Casey T, Folland CK, Colman A, Mehta V (1999) Interdecadal modulation of the impact of ENSO on Australia. Clim Dyn 15:319-323. https://doi.org/10.1007/s003820050284

Song J, Klotzbach PJ (2018) What has controlled the poleward migration of annual averaged location of tropical cyclone lifetime maximum intensity over the western North Pacific since 1961? Geophys Res Lett 45:1148-1156. https://doi. org/10.1002/2017GL076883

Stuecker MF, Timmermann A, Jin F-F, McGregor S, Ren H-L (2013) A combination mode of the annual cycle and the El Niño/Southern Oscillation. Nat Geosci 6:540-544. https://doi.org/10.1038/ ngeo 1826

Stuecker MF, Jin F-F, Timmermann A, McGregor S (2015) Combination mode dynamics of the anomalous northwest Pacific anticyclone. J Clim 28:1093-1111. https://doi.org/10.1175/ JCLI-D-14-00225.1

Tao L, Wu L, Wang Y, Yang J (2012) Influence of Tropical India Ocean warming and ENSO on tropical cyclone activity over the Western North Pacific. J Meteorol Soc Jpn 90:127-144. https:// doi.org/10.2151/jmsj.2012-107

Tung KK, Chen XY, Zhou JS, Li KF (2019) Interdecadal variability in pan- Pacific and global SST, revisited. Clim Dyn 52:21452157. https://doi.org/10.1007/s00382-018-4240-1

Wang B, Chan JCL (2002) How strong ENSO events affect tropical storm activity over the western North Pacific. J Clim 15:16431658. https://doi.org/10.1175/1520-0442(2002)015\%3c164 3:HSEEAT\%3e2.0.CO;2

Wang C, Wu L (2016) Interannual shift of the tropical upper-tropospheric trough and its influence on tropical cyclone formation over the western North Pacific. J Clim 29:4203-4211. https:// doi.org/10.1175/JCLI-D-15-0653.1

Wang B, Wu R, Fu X (2000) Pacific-east Asian teleconnection: how does ENSO affect east Asian climate? J Clim 13:1517-1536. 
https://doi.org/10.1175/1520-0442(2000)013\%3c1517:PEATH $\mathrm{D} \% 3 \mathrm{e} 2.0 . \mathrm{CO} ; 2$

Wang B, Xiang B, Lee J-Y (2013) Subtropical High predictability establishes a promising way for monsoon and tropical storm predictions. Proc Natl Acad Sci 110:2718-2722. https://doi. org/10.1073/pnas.1214626110

Wu L, Wang C, Wang B (2015) Westward shift of western North Pacific tropical cyclogenesis. Geophys Res Lett 42:1537-1542. https://doi.org/10.1002/2015GL063450

Xiang B, Wang B, Yu W, Xu S (2013) How can anomalous western North Pacific Subtropical High intensify in late summer? Geophys Res Lett 40:2349-2354. https://doi.org/10.1002/grl.50431

Xie S-P, Hu K, Hafner J, Tokinaga H, Du Y, Huang G, Sampe T (2009) Indian Ocean capacitor effect on Indo-western Pacific climate during the summer following El Niño. J Clim 22:730 747. https://doi.org/10.1175/2008JCLI2544.1

Yu J, Li T, Tan Z, Zhu Z (2016) Effects of tropical North Atlantic SST on tropical cyclone genesis in the western North Pacific. Clim Dyn 46:865-877. https://doi.org/10.1007/s0038 2-015-2618-X

Zhan R, Wang Y, Lei X (2011a) Contributions of ENSO and East Indian Ocean SSTA to the interannual variability of northwest Pacific tropical cyclone frequency. J Clim 24:509-521. https:// doi.org/10.1175/2010JCLI3808.1

Zhan R, Wang Y, Wu C-C (2011b) Impact of SSTA in the East Indian Ocean on the frequency of northwest Pacific tropical cyclones: a regional atmospheric model study. J Clim 24:6227-6242. https:// doi.org/10.1175/JCLI-D-10-05014.1
Zhan R, Wang Y, Tao L (2014) Intensified impact of East Indian Ocean SST anomaly on tropical cyclone genesis frequency over the western North Pacific. J Clim 27:8724-8739. https://doi.org/10.1175/ JCLI-D-14-00119.1

Zhang W, Vecchi GA, Murakami H, Villarini G, Delworth TL, Yang X, Jia L (2018) Dominant Role of Atlantic Multidecadal Oscillation in the recent decadal changes in western North Pacific tropical cyclone activity. Geophys Res Lett 45:354-362. https://doi. org/10.1002/2017GL076397

Zhao H, Wang C (2019) On the relationship between ENSO and tropical cyclones in the western North Pacific during the boreal summer. Clim Dyn 52:275-288. https://doi.org/10.1007/s0038 2-018-4136-0

Zhao H, Wang C, Yoshida R (2016) Modulation of tropical cyclogenesis in the western North Pacific by the quasi-biweekly oscillation. Adv Atmos Sci 33:1361-1375. https://doi.org/10.1007/s0037 6-016-5267-z

Zhao H, Duan X, Raga GB, Klotzbach PJ (2018a) Changes in characteristics of rapidly intensifying western North Pacific tropical cyclones related to climate regime shifts. J Clim 31:8163-8179. https://doi.org/10.1175/JCLI-D-18-0029.1

Zhao J, Zhan R, Wang Y, Xu H (2018b) Contribution of Interdecadal Pacific Oscillation to the recent abrupt decrease in tropical cyclone genesis frequency over the western North Pacific since 1998. J Clim 31:8211-8224. https://doi.org/10.1175/JCLI-D-18-0202.1

Publisher's Note Springer Nature remains neutral with regard to jurisdictional claims in published maps and institutional affiliations. 